NOTICE: This is the author's version of a work that was accepted for publication in Composites Part B. Changes resulting from the publishing process, such as peer review, editing, corrections, structural formatting, and other quality control mechanisms may not be reflected in this document. Changes may have been made to this work since it was submitted for publication. A definitive version was subsequently published in Composites Part B, Vol. 60 (2014). doi:

10.1016/j.compositesb.2013.12.036 


\title{
Synthesis and mechanical properties of cotton fabric reinforced geopolymer composites
}

T. Alomayri ${ }^{\text {a, b }}$, F.U.A. Shaikh ${ }^{\text {c }}$ I.M. Low ${ }^{\mathrm{a}, *}$

a Department of Imaging \& Applied Physics, Curtin University, GPO Box U1987, Perth, WA 6845, Australia.

b Department of Physics, Umm Al-Qura University, Makkah 21955, Saudi Arabia.

${ }^{\mathrm{c}}$ Department of Civil Engineering, Curtin University, GPO Box U1987, Perth, WA 6845, Australia.

*Corresponding author. Email: j.low@curtin.edu.au

\begin{abstract}
Geopolymer composites reinforced with different layers of woven cotton fabric are fabricated using lay-up technique. Mechanical properties, such as flexural strength, flexural modulus, impact strength and fracture toughness of geopolymer composites reinforced with 3.6, 4.5, 6.2 and $8.3 \mathrm{wt} \%$ cotton fibres are studied. The fracture surfaces of the composites are also examined using scanning electron microscopy. The results show that all the mechanical properties of the composites are improved by increasing the cotton fibre contents. It is found that the mechanical properties of cotton fabric reinforced geopolymer composites are superior to pure geopolymer matrix.
\end{abstract}

Keywords: A. Polymer-matrix composites, B. Microstructures, B. Mechanical properties, B. Fracture toughness.

\section{Introduction}


Geopolymers are inorganic compounds that can be cured and hardened at near-ambient temperatures to form materials that are effectively low-temperature ceramics with typical temperature resistance and strength [1]. In recent years, geopolymers have emerged as an alternative to cements $[2,3]$. However, despite their many desirable attributes, such as relatively high strength, elastic modulus and low shrinkage, geopolymers suffer from brittle failure like most ceramics. Nevertheless, this limitation can be overcome by the introduction of reinforcing materials, including short fibres or unidirectional long fibres into the geopolymer matrix. For this purpose, various inorganic fibres have been previously used as reinforcement in geopolymer composites [4-7].

However, contemporary concerns over environment and climate change have given rise to an increasing interest in natural materials to produce environmentally friendly composite materials for construction. Natural fibres are very attractive for composite materials as they have several useful characteristics, such as low cost, low density, availability, recyclability, and renewability. In addition, they possess excellent mechanical properties like high degrees of toughness, flexibility, specific modulus and specific strength $[8,9]$.

For these reasons, natural fibres are more attractive to researchers and scientists as an alternative source of reinforcement to develop organic polymer composites. As an illustration, cellulose fibres have been used to reinforce various organic matrices like polyester, vinyl ester, and epoxy matrices [10-13]. However, at present there has been limited published research on the use of natural fibres to reinforce inorganic matrices despite the advantages they offer in terms of low cost, ready availability, low toxicity and good mechanical strength [14]. In a previous report, the authors studied the mechanical properties of short cotton fibre-reinforced geopolymer composites. Results showed that further increases 
in short cotton fibre content beyond $0.5 \mathrm{wt} \%$ caused a reduction in the mechanical properties due to poor workability which led to formation of voids and fibre agglomerations $[15,16]$. In a follow-up work by the same authors [17], similar behaviour has been reported in cotton fabric-reinforced geopolymer composites, with the exception that the mechanical properties decreased beyond $2.1 \mathrm{wt} \%$ cotton fibres. This decrease was attributed to the poor bond between the cotton fibre and matrix due to insufficient amount of geopolymer matrix in the composites containing more than $2.1 \%$ wt $\%$ cotton fibres.

In the present study, woven cotton fabrics $(\mathrm{CF})$ have been impregnated (wet out) with geopolymer paste, stacked, and compressed by a roller to force the paste to penetrate the fabric and to remove most of the trapped air. The aim is to investigate the possibility of applying above technique to manufacture geopolymer composites with cotton fabrics for structural applications, and to examine the basic mechanical properties through experimental testing. Useful results have been gathered for composites with various cotton fibres contents $(0,3.6,4.5,6.2$ and $8.3 \mathrm{wt} \%)$ under the three-point bending test. The results show that the addition of cotton fibres improves the mechanical properties of geopolymer composites such as flexural strength, flexural modulus, impact strength and fracture toughness. Synchrotron radiation diffraction (SRD) and scanning electron microscopy (SEM) are used to characterise the phase composition, microstructure, and failure mechanisms of woven cotton fibre reinforced geopolymer composites.

\section{Experimental investigation}

\subsection{Materials}


Cotton fabric (CF) of $30 \mathrm{~cm} \times 7.5 \mathrm{~cm}$ was used to reinforce the geopolymer. This fabric is made up of yarns with a density of $1.54 \mathrm{~g} / \mathrm{cm}^{3}$, tensile strength of $400 \mathrm{MPa}$, and Young's modulus of 4.8 GPa. Low calcium fly-ash (ASTM class F), collected from Collie power station in Western Australia, was used as the source material of the geopolymer matrix. The chemical composition of fly-ash (FA) is shown in Table 1. The alkaline activator for geopolymerisation was a combination of sodium hydroxide solution and sodium silicate grade D solution. Sodium hydroxide flakes with $98 \%$ purity were used to prepare the solution. The chemical composition of sodium silicate used was $14.7 \% \mathrm{Na}_{2} \mathrm{O}, 29.4 \% \mathrm{SiO}_{2}$ and $55.9 \%$ water by mass.

\subsection{Preparation of geopolymer composites}

To cast the composite samples, five wooden moulds with open tops were prepared and greased to avoid the samples sticking during de-moulding. The fabrics were pre-dried for 60 minutes at $70{ }^{\circ} \mathrm{C}$. An 8 molar concentration of sodium hydroxide solution was prepared and combined with the sodium silicate solution one day before mixing. The fly ash and alkaline solution were mixed in a Hobart mixer to form a homogeneous paste. A thin layer of geopolymer paste was first spread in the wooden mould and the first layer of woven fabric was carefully laid on that layer. The fabric was then fully impregnated (wet out) with geopolymer paste by a roller and the process repeated for the desired number of cotton fibre layers. Each specimen contained different layers of cotton fabric (see Table 2) with final layer being geopolymer paste. The alkaline solution to fly ash ratio was fixed at 0.35 whereas the ratio of sodium silicate solution to sodium hydroxide solution was maintained at 2.5 . The composite specimens were placed on a vibration table in order to ensure better penetration of the matrix between the fabric openings and to remove the entrapped air voids. Then, the composite specimens were pressed under $25 \mathrm{~kg}$ load for 3 hours. Subsequently, the specimens 
were covered with plastic film and cured at $80{ }^{\circ} \mathrm{C}$ in an oven for 24 hours. The samples were de-moulded and kept in room condition for 28 days before testing. The mechanical properties of unreinforced geopolymer used in this study are measured and used for comparison purpose. Typically, the compressive strength of the geopolymer paste is $21 \mathrm{MPa}$ with density of $1.9 \mathrm{~g} / \mathrm{cm}^{3}$.

\subsection{Characterisation}

\subsubsection{Synchrotron Radiation Diffraction (SRD)}

The Powder Diffraction beamline at the Australian Synchrotron was used to collect the diffraction patterns of fly-ash and the geopolymer composites. The diffraction pattern of each sample was collected using a wavelength of $0.825 \AA$ over the $2 \theta$ range of $5^{\circ}-45^{\circ}$.

\subsubsection{Scanning Electron Microscopy (SEM)}

The microstructures of geopolymer composites were examined using a Zeiss Evo 40XVP scanning electron microscope. The specimens were mounted on aluminium stubs using carbon tape and then coated with a thin layer of platinum to prevent charging before the observation.

\subsection{Mechanical properties}

\subsubsection{Flexural strength}

Rectangular bars with a length of $60 \mathrm{~mm}$ were cut from the fully cured samples and subjected to three-point bend tests to evaluate their flexural strength. The tests were performed in a LLOYD Material Testing Machine (50 kN capacity) with a displacement rate of 0.5 $\mathrm{mm} /$ minute. Five specimens of each composition were tested. The flexural strength $\left(\sigma_{F}\right)$ was determined using the following equation [9]: 
$\sigma_{F}=\frac{3}{2} \frac{P_{m} S}{B W^{2}}$

where $P_{m}$ is the maximum load at crack extension, $S$ is the span of the sample, $B$ is the specimen width and $W$ is the specimen thickness (depth).

Values of the flexural modulus $\left(\mathrm{E}_{\mathrm{F}}\right)$ were computed using the initial slope of the loaddisplacement curve, $\Delta P / \Delta X$, using the following formula [9]:

$$
E_{F}=\frac{S^{3}}{4 B W^{3}}\left(\frac{\Delta P}{\Delta X}\right)
$$

\subsubsection{Impact strength}

The impact strength was determined using a Zwick Charpy impact tester with a $7.5 \mathrm{~J}$ pendulum hammer. Five bars of $60 \mathrm{~mm}$ long were utilised. The impact strength $\left(\sigma_{i}\right)$ was calculated using the following equation [18]:

$$
\sigma_{i}=\frac{E}{A}
$$

where $E$ is the impact energy required to break a sample with a ligament of area $A$.

\subsubsection{Fracture toughness}

Rectangular bars of $60 \mathrm{~mm}$ long and cross-sectional dimension of 20 x $20 \mathrm{~mm}$ were used in the fracture toughness measurements. A crack with a length to thickness (depth) $(a / W)$ ratio of 0.4 was introduced into the specimen using a $0.4 \mathrm{~mm}$ diamond blade to evaluate the fracture toughness. The fracture toughness $K_{I C}$ was calculated using the following equation:

$$
K_{I C}=\frac{p_{m} S}{B W^{3 / 2}} f\left(\frac{a}{W}\right)
$$


where $P_{m}$ is the maximum load at crack extension, $S$ is the span of the sample, $B$ is the specimen width, $W$ is the specimen thickness (depth), $a$ is the crack length where $f(a / W)$ is the polynomial geometrical correction factor given by [9]:

$$
f\left(\frac{a}{W}\right)=\frac{3(a / W)^{1 / 2}\left[1.99-(a / W)(1-a / W) \times\left(2.15-3.93 a / W+2.7 a^{2} / W^{2}\right)\right]}{2(1+2 a / W)(1-a / W)^{3 / 2}}
$$

\section{Results and discussion}

\subsection{Synchrotron radiation diffraction}

The synchrotron radiation diffraction (SRD) patterns of class F fly ash, cotton fibres, and geopolymer composites containing $0,3.6,4.5,6.2$ and $8.3 \mathrm{wt} \%$ of cotton fibres, are shown in

Fig.1. The crystalline phases present were indexed using Powder Diffraction Files (PDFs) from the Inorganic Crystal Structure Database (ICSD). The diffraction pattern of cotton fibres shows typical characteristic peaks, indicating the presence of cellulose. The SRD pattern of fly ash shows that the major crystalline phases are quartz, mullite and hematite. These crystalline phases are the main component of fly ash. When comparing the SRD pattern of the original fly ash with those of the hardened geopolymeric materials shown in Fig. 1, it is seen that the crystalline phases of quartz, mullite and hematite remain unchanged and have not been visibly altered by the activation reaction. This finding confirms that the crystalline phases are not reactive or involved in geopolymerisation, but simply present as inactive fillers in geopolymer network [18-21]. In this case, however, amorphous aluminosilicate phases are more reactive and dissolvable in alkaline solution during the formation of a geopolymer [2224].

\subsection{Mechanical properties}

3.2.1. Flexural strength and modulus 
Flexural tests are often used to characterise the mechanical properties of layered materials since they provide a simple means of determining the bending response. This provides useful information on the performance of layered fabric-based composites [25]. The test results show that the flexural strength of cotton fabric reinforced composite increases as wt $\%$ of cotton fibres increase (see Fig. 2). The composite containing $8.3 \mathrm{wt} \%$ woven cotton fibres exhibited the highest flexural strength among all composites. The flexural strength of the composites increased from 8.2 MPa to 31.7 MPa compared to pure geopolymer. This indicates that increasing the number of woven cotton fibres leads to considerable improvement in flexural strength in the composite. This finding can be justified from the fact that the flexural strength is controlled by the number of reinforcement layers. The lower weight of cotton fabrics allows multiple layers of fabric in the composite, to resist the shear failure and contribute in sustaining the applied load to the composites. This permits greater stress transfer between the matrix and the cotton fibres, resulting in improved flexural strength [26].

In previous studies $[15,16]$, the authors studied the flexural behaviour of short cotton fibre reinforced geopolymer composites and observed minimum improvement in the flexural strength over that of the unreinforced specimens due to poor dispersion of short cotton fibres in the matrix. In fact, agglomerations of cotton fibres were noticed which degraded the interfacial adhesion between the fibre and the matrix as shown in Fig. 6. In present study, the utilisation of continuous fibres as reinforcement for geopolymer composites has shown better mechanical properties than short cotton fibres, owing to their ability to effectively bridge the cracks due to their alignment in the direction of tension resulted in greater stress transfer at the interface of the composites. The improved performance of cotton fabric-geopolymer composite can be explained by observing the SEM microscope images as seen in Fig. 7F. 
This shows good penetration of geopolymer paste into the filament of the cotton bundle making up the fabric, providing improved bonding between the fabric and the geopolymer matrix and leading to an improvement in flexural strength.

The flexural modulus of geopolymer composites is shown in Fig. 3 and indicates similar trends to flexural strength values. In reality, the addition of woven cotton fibres in the geopolymer matrix increases the flexural modulus over plain geopolymer matrix. The flexural modulus is a measure of resistance to deformation of the composite in bending. It was observed that none of the specimens are completely broken at peak load. This could be due to the crack bridging by long continuous fibres, which makes their flexural modulus higher than un-reinforced geopolymer. Such fibres are able to withstand a higher load and are capable of undergoing multiple cracks throughout the loading process, thus prevent brittle failure of the specimens. Similar results have been reported by Low et al. [9] when testing the mechanical properties of cellulose fibre-reinforced epoxy laminates using the three point bending test. They report an increase in both flexural strength and modulus as the fibre contents increase.

The increase in woven cotton fibre content was exceptionally useful in terms of improving the flexural strength and modulus of this inorganic polymer matrix.

\subsubsection{Impact strength}

Impact strength is an essential dynamic property of engineering material that gives an indication of its resistance against sudden impact. The impact strength of fibre reinforced polymer is governed by the matrix-fibre interfacial bonding, and properties of matrix and fibres. When the composites undergo a sudden force, the impact energy is dissipated by the 
combination of fibre pull outs, fibre fracture and matrix deformation [27, 28]. The experimental results presented in Fig. 4 indicate that the impact strength of the composites increases as cotton fibre content increases. The impact strength of the neat geopolymer increased from 2.1 to $15.6 \mathrm{~kJ} / \mathrm{m}^{2}$ after the addition of $8.3 \mathrm{wt} \%$ woven cotton fabric to the geopolymer composite. This significant enhancement in impact strength could be the result of pressing the top surface of the geopolymer composites, which expelled the trapped air from the sample and forced the geopolymer paste into the voids and pore spaces. As a result, the bonding between the fabrics and the matrix is enhanced, and results in increased impact strength.

This improvement in impact strength may also be attributed to the fibrillation of cotton layers that creates branches in the fibre (see Fig. 7G), resulting in the formation of micro fibrils which increase the fibre specific surface area $[29,30]$. This results in an enhanced fibrematrix interaction, and a strong bonding between the micro fibrils and the geopolymer matrix. Therefore, better stress transfer from the matrix to the micro fibrils results in increased fibre-matrix bonding. Similar remarkable improvements in impact strength was reported by Graupner [31 ]. Based in his observation, the addition of cotton fibre increased the impact strength of pure poly (lactic acid) (PLA) matrix. He concluded that the increase was due to greater elongation of cotton fibres at break. Fibres containing much cellulose generally have high elongation at break values. Cotton has a cellulose content of about $88-96 \%$. Elongation at break and impact strength are directly correlated. The high elongation at break of cotton fibres increased the elongation at break in the composites, leading to higher impact strength.

\subsubsection{Fracture toughness}


Generally, crack deflection, debonding and bridging of fibres slows down the crack propagation in fibre reinforced composites and increase the fracture energy [32-37].

Fig. 5 shows the influence of cotton fabric content on the fracture toughness of the composites, the composite containing higher cotton fibre content exhibits higher fracture toughness. The greatest improvement in fracture toughness (from about $0.6 \mathrm{MPa} \cdot \mathrm{m}^{1 / 2}$ in the unreinforced matrix to about $1.8 \mathrm{MPa} . \mathrm{m}^{1 / 2}$ ) was obtained with $8.3 \mathrm{wt} \%$ cotton fibre reinforcement. This extraordinary enhancement is due to the unique properties of woven cotton fibre to resist fracture resulted in increased energy dissipation from crack-deflection at fibre-matrix interface, fibre-debonding, fibre-bridging, fibre pull-out and fibre-fracture. The high values of fracture toughness obtained in geopolymer composites with woven cotton fibres were due to better interaction between fibre and matrix as shown in Fig. 7. The improved interfacial adhesion enabled higher stress transfer between the fibres and matrix and reduced the chance of fibre de-bonding. Accordingly, the load required to break the sample increases when the content of cotton fibre is increased. Therefore, the fracture toughness of geopolymer composites increases with increasing wt $\%$ of cotton fibres.

Fig. 7E demonstrates selected scanning electron micrographs of fracture surface of geopolymer composite and explains the fracture toughness behaviour. It can be seen from Fig. 7E that small pieces of geopolymer paste were attached to the fibre surface of cotton fibre/geopolymer composites. Hence, retention of the matrix on the fibre surfaces shows the good adhesion between cotton fibres and geopolymer matrix. Additionally, it was observed that geopolymer composites with woven cotton fibres did not completely break into two pieces due to close spacing of woven cotton fabric which lead to fibres bridging the cracks 
and enhancing the crack propagation resistance. The tortuous pathway of the crack propagation indicates that high energy is absorbed by the cotton fibre layers (see Fig. 8).

\subsection{Microstructure characteristics}

The fracture surfaces of the woven cotton fibre reinforced geopolymer composites have been studied under SEM and are shown in Fig. 7. Generally, fibre pullout, fibre-debonding, fibre breakage and matrix fracture are observed after the fracture test of all composites. In fact, such toughening mechanisms increased the fracture properties of samples reinforced with woven cotton fibres. The effect of fibre content on the fracture surface is clearly seen in Figs. 7A and B. Composites filled with lower fibre content (3.6 and 4.5) wt $\%$ show an increase in matrix-rich regions compared to composites filled with higher fibre content. An increase in matrix rich regions means that the matrix is not reinforced by enough fibres. Therefore, there are insufficient fibres to transfer the load from the matrix [37]. Due to this reason, the geopolymer composites with low fibre content exhibited low fracture toughness and mechanical properties. However, Figs. 7C and D illustrate the fracture surfaces of the geopolymer composites with higher fibre content. It can be seen that there are higher fibrerich regions of composites filled with 6.2 and $8.3 \mathrm{wt} \%$ cotton fibres. An increase in fibre-rich regions means greater stress-transfer from the matrix to the cotton fibres thereby resulting in the improvement of mechanical properties.

Therefore, these observations indicate that the woven cotton fabrics can be used as potential material to reinforce geopolymer composites due to their good mechanical properties.

\section{Conclusions}


This study on mechanical properties of cotton fabric-reinforced geopolymer composite shows that the presence of cotton fabric layers in the geopolymer paste significantly increases all mechanical properties (flexural strength, flexural modulus, impact strength and fracture toughness) compared to neat geopolymer. This remarkable enhancement is due to the unique properties of cotton fibre in withstanding greater bending and fracture forces than the more brittle geopolymers. SEM micrographs show a number of toughness mechanisms, such as crack bridging, fibre pullout and fibre fracture, and matrix fracture. These toughening mechanisms of cotton fabric-reinforced geopolymer composites are the major factors contributing to the enhanced mechanical properties of samples reinforced with cotton fabric. Cotton fibres appear to be uniquely suited to reinforce the geopolymer composites since they process easily under conventional manufacturing techniques to yield a product with good mechanical properties at low cost. They can be classified as desirable performing composites that offer benefits to engineers, particularly in less developed countries or countries that need low-cost construction materials. Possible applications for cotton fibre-reinforced geopolymer composites include slabs or shingles for siding, certain types of roofing, and some interior uses in the building structure. They may also be used for other applications such as pipes and cooling towers.

\section{Acknowledgements}

The authors would like to thank Mr. X. Tony from the Department of Applied Physics at Curtin University for his assistance with SEM. The authors also thank Mr. Andreas Viereckle of Mechanical Engineering at Curtin University for assistance with Charpy impact test. The collection of diffraction data was funded by the Australian Synchrotron. 


\section{References}

[1] Goretta KC, Chen N, Gutierrez-Mora F, Routbort JL, Lukey GC, van Deventer JSJ. Solid-particle erosion of a geopolymer containing fly ash and blast-furnace slag. Wear 2004;256(7):714-9.

[2] Davidovits J. Geopolymers: inorganic polymeric new materials. J Therm Anal 1991;37(8):1633-56.

[3] Temuujin J, van Riessen A, MacKenzie KJD. Preparation and characterisation of fly ash based geopolymer mortars. Constr Build Mater 2010;24(10):1906-10

[4] Lin T, Jia D, He P, Wang M, Liang D. Effects of fiber length on mechanical properties and fracture behavior of short carbon fiber reinforced geopolymer matrix composites. Mater Sci Eng 2008;497(1-2):181-5.

[5] Wang H, Li H, Yan F. Synthesis and tribological behavior of metakaolinite-based geopolymer composites. Mater Lett 2005; 9(29-30):3976-81.

[6] Zhao Q, Nair B, Rahimian T, Balaguru P. Novel geopolymer based composites with enhanced ductility. J Mater Sci 2007;42(9):3131-7.

[7] Silva FJ, Thaumaturgo C. Fibre reinforcement and fracture response in geopolymeric mortars. Fract Eng Mater Struct 2003;26(2):167-72.

[8] Dhakal HN, Zhang ZY, Richardson MW. Effect of water absorption on the mechanical properties of hemp fibre reinforced unsaturated polyester composites. Compos Sci Technol 2007;67(7-8):1674-83. 
[9] Low IM, McGrath M, Lawrence D, Schmidt P, Lane J, Latella BA, et al. Mechanical and fracture properties of cellulose-fibre-reinforced epoxy laminates. Compos Part A: Appl Sci Manuf 2007;38(3):963-74.

[10] Alhuthali A, Low IM. Mechanical properties of cellulose fibre reinforced vinyl-ester composites in wet conditions. J Mater Sci 2013;48(18):6331-40.

[11] Alhuthali A, Low IM, Dong C. Characterisation of the water absorption, mechanical and thermal properties of recycled cellulose fibre reinforced vinyl-ester econanocomposites. Compos Part B: Eng 2012;43(7):2772-81.

[12] Alamri H, Low IM, Alothman Z. Mechanical, thermal and microstructural characteristics of cellulose fibre reinforced epoxy/organoclay nanocomposites. Compos Part B: Eng 2012;43(7):2762-71.

[13] Alamri H, Low IM. Effect of water absorption on the mechanical properties of nanoclay filled recycled cellulose fibre reinforced epoxy hybrid nanocomposites. Compos Part A: Appl Sci Manuf 2013;44(0):23-31.

[14] Alzeer M, MacKenzie K. Synthesis and mechanical properties of novel composites of inorganic polymers (geopolymers) with unidirectional natural flax fibres (phormium tenax). Appl Clay Sci 2013; 76(0):148-52.

[15] Alomayri T, Shaikh FUA, Low IM. Characterisation of cotton fibre-reinforced geopolymer composites. Compos Part B Eng:2013;50(0):1-6.

[16] Alomayri T, Low IM. Synthesis and characterization of mechanical properties in cotton fiber-reinforced geopolymer composites. J Asian Ceram Soc 2013;1(1):30-4.

[17] Alomayri T, Shaikh FUA, Low IM. Thermal and mechanical properties of cotton fabric-reinforced geopolymer composites. J Mater Sci 2013;48(19):6746-52. 
[18] Fernández-Jiménez A, Palomo A. Composition and microstructure of alkali activated fly ash binder: effect of the activator. Cem Concr Res 2005;35(10):1984-92.

[19] Fernández-Jiménez A, Palomo A. Characterisation of fly ashes. Potential reactivity as alkaline cements. Fuel 2003;82(18):2259-65.

[20] Rattanasak U, Chindaprasirt P. Influence of $\mathrm{NaOH}$ solution on the synthesis of fly ash geopolymer. Miner Eng 2009;22(12):1073-8.

[21] Rickard WDA, Williams R, Temuujin J, van Riessen A. Assessing the suitability of three Australian fly ashes as an aluminosilicate source for geopolymers in high temperature applications. Mater Sci Eng 2011;528(9):3390-7.

[22] Chen-Tan NW, Van Riessen A, Ly CV, Southam DC. Determining the reactivity of a fly ash for production of geopolymer. J Am Ceram Soc 2009;92(4):881-7.

[23] Xu H, Van Deventer JSJ. The geopolymerisation of alumino-silicate minerals. J Miner Process 2000;59(3):247-66.

[24] Xu H, Van Deventer JSJ. Geopolymerisation of multiple minerals. Miner Eng 2002;15(12):1131-9.

[25] Abanilla MA, Karbhari VM, Li Y. Interlaminar and intralaminar durability characterization of wet layup carbon/epoxy used in external strengthening. Compos Part B: Eng 2006;37(7-8):650-61.

[26] Sim J, Park C, Moon DY. Characteristics of basalt fiber as a strengthening material for concrete structures. Compos Part B: Eng. 2006;36(6-7):504-512.

[27] Alamri H, Low IM. Mechanical properties and water absorption behaviour of recycled cellulose fibre reinforced epoxy composites. Polym Test 2012;31(5):620-8. 
[28] Mishra S, Mohanty AK, Drzal LT, Misra M, Parija S, Nayak SK, Tripathy SS. Studies on mechanical performance of biofibre/glass reinforced polyester hybrid composites. Compos Sci Technol 2003;63(10):1377-85.

[29] Zhang W, Okubayashi S, Bechtold T. Fibrillation tendency of cellulosic fibers part 3: effects of alkali pretreatment of lyocell fiber. Carbohydr Polym. 2005;59(2):173-9.

[30] Nakagaito AN, Yano H. The effect of morphological changes from pulp fibre towards nano-scale fibrillated cellulose on the mechanical properties of high-strength plant fibre based composites. Appl Phys A 2004;78(4):547-52.

[31] Graupner N. Application of lignin as natural adhesion promoter in cotton fibrereinforced poly(lactic acid) (PLA) composites. J Mater Sci 2008;43(15):5222-9.

[32] Reis JML. Fracture and flexural characterization of natural fiber-reinforced polymer concrete. Constr Build Mater 2006;20(9):673-8.

[33] Silva FDA, Filho RDT, Filho JDA, Fairbairn EDM. Physical and mechanical properties of durable sisal fibre-cement composites. Constr Build Mater 2010;24(5):777-85.

[34] Silva FDA, Mobasher B, Filho RDT. Cracking mechanisms in durable sisal fiber reinforced cement composites. Cem Concr Compos 2009;31(10):721-30.

[35] Tolêdo Filho RD, Ghavami K, England GL, Scrivener K. Development of vegetable fibre-mortar composites of improved durability. Cem Concr Compos 2003;25(2):18596.

[36] Tolêdo Filho RD, Scrivener K, England GL, Ghavami K. Durability of alkalisensitive sisal and coconut fibres in cement mortar composites. Cem Concr Compos 2000;22(2):127-43. 
[37] Joseph PV, Joseph K, Thomas S. Effect of processing variables on the mechanical properties of sisal fiber-reinforced polypropylene composites. Compos Sci Technol 1999;59(11):1625-40 


\section{Figure Captions}

1. Synchrotron radiation diffraction patterns of (A) cotton fibres (CF), (B) fly-ash, and geopolymer composite with (C) $3.6 \mathrm{wt} \% \mathrm{CF}$, (D) $4.5 \mathrm{wt} \% \mathrm{CF}$, (E) $6.2 \mathrm{wt} \% \mathrm{CF}$ and (F) 8.3 wt\% CF. [Legend: 1 = mullite (PDF 15-0776), 2 = quartz (PDF 05-0490), $3=$ hematite (PDF 13-0534), 4= cellulose (PDF 00-060-1502) ].

2. Flexural strength of geopolymer composites as a function of fibre content

3. Flexural modulus of geopolymer composites as a function of fibre content.

4. Impact strength of geopolymer composites as a function of fibre content.

5. Fracture toughness of geopolymer composites as a function of fibre content.

6. SEM showing agglomeration of short fibres in cotton fibre/geopolymer composites loaded with $1.0 \mathrm{wt} \%$.

7. SEM images of the fracture surface for geopolymer composites reinforced with varying content of cotton fibres (A) 3.6, (B) 4.5, (C) 6.2 and (D-E) 8.3wt\%. The micrographs of (F) penetration of the geopolymer matrix into cotton fabrics and (G) micro fibrillation of cotton fibers.

8. Optical image of crack propagation in cotton fabric/geopolymer composites loaded with $8.3 \mathrm{wt} \%$ fibre. 


\section{List of Tables}

Table1: Chemical composition of fly ash.

\begin{tabular}{lllllllll}
\hline $\mathrm{SiO}_{2}$ & $\mathrm{Al}_{2} \mathrm{O}_{3}$ & $\mathrm{Fe}_{2} \mathrm{O}_{3}$ & $\mathrm{CaO}$ & $\mathrm{MgO}$ & $\mathrm{SO}_{3}$ & $\mathrm{Na}_{2} \mathrm{O}$ & $\mathrm{K}_{2} \mathrm{O}$ & LOI \\
\hline $50 \%$ & $28.25 \%$ & $13.5 \%$ & $1.78 \%$ & $0.89 \%$ & $0.38 \%$ & $0.32 \%$ & $0.46 \%$ & $1.64 \%$
\end{tabular}

Table 2: Formulations of samples.

\begin{tabular}{lcc}
\hline Sample & Fabric layers & Fibre content \\
& & $(\mathrm{wt} \%)$ \\
\hline Composite 0 & 0 & 0 \\
Composites 1 & 5 & 3.6 \\
Composites 2 & 10 & 4.5 \\
Composites 3 & 20 & 6.2 \\
Composites 4 & 40 & 8.3
\end{tabular}


Fig. 1

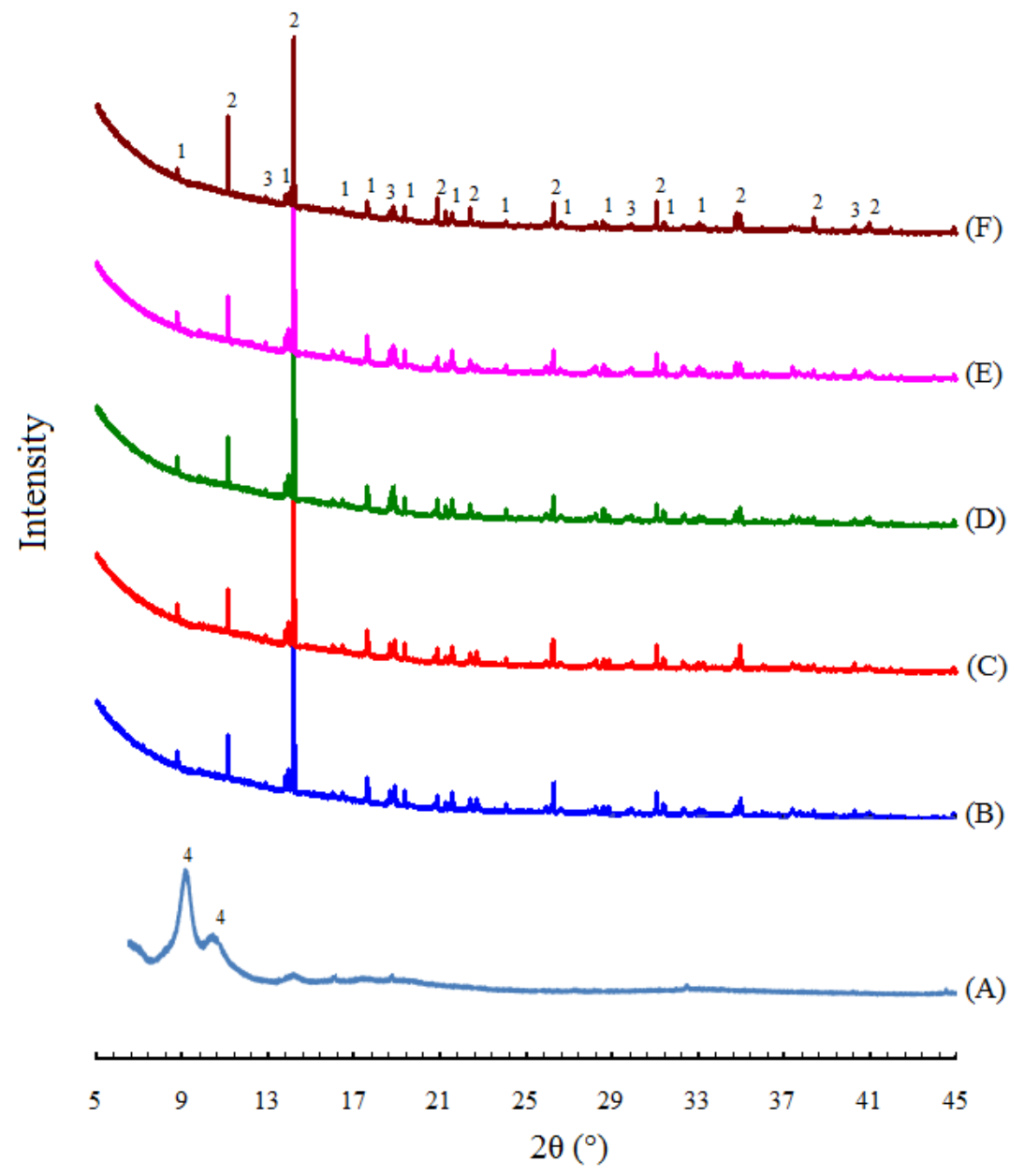


Fig. 2

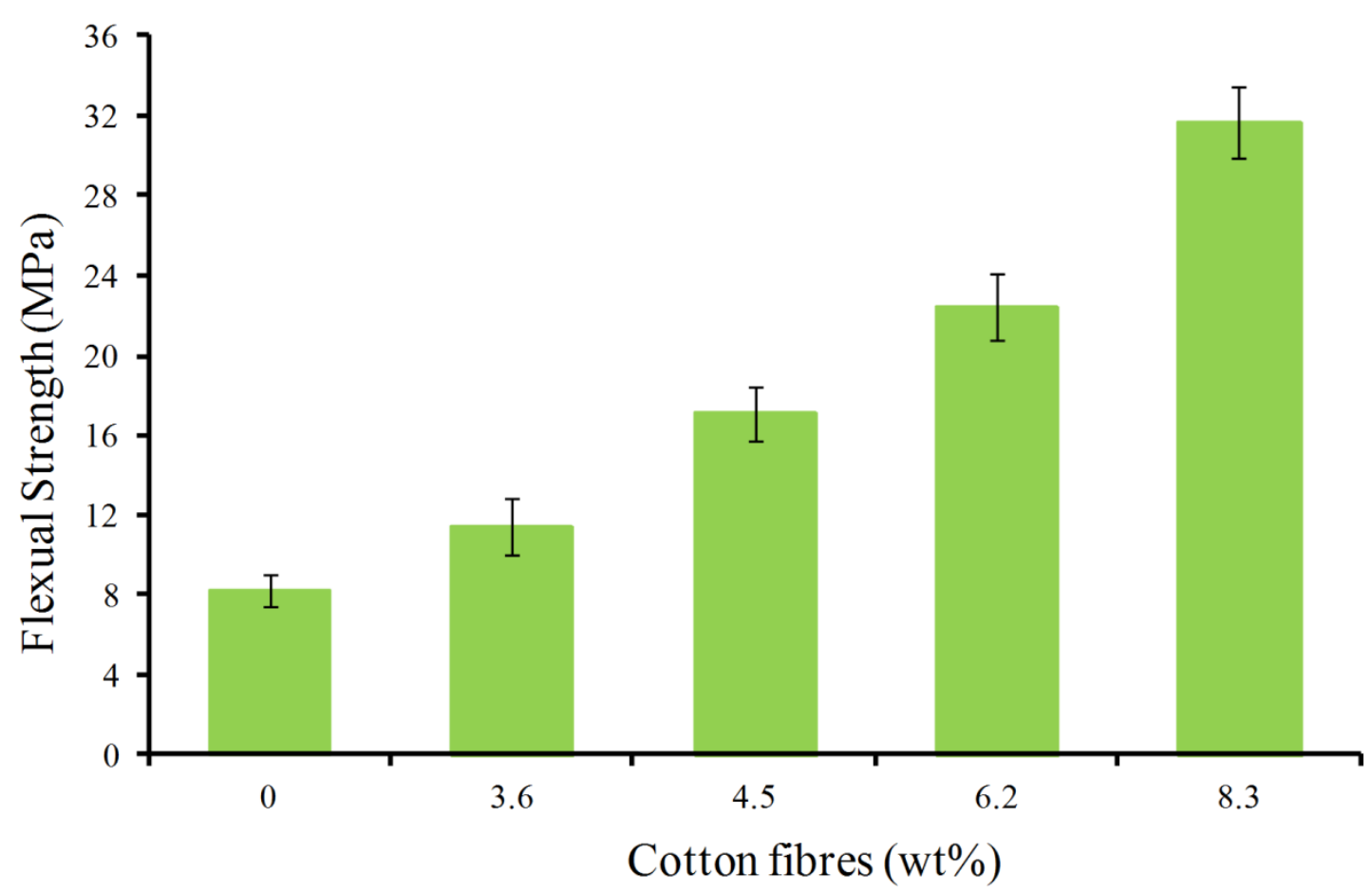


Fig. 3

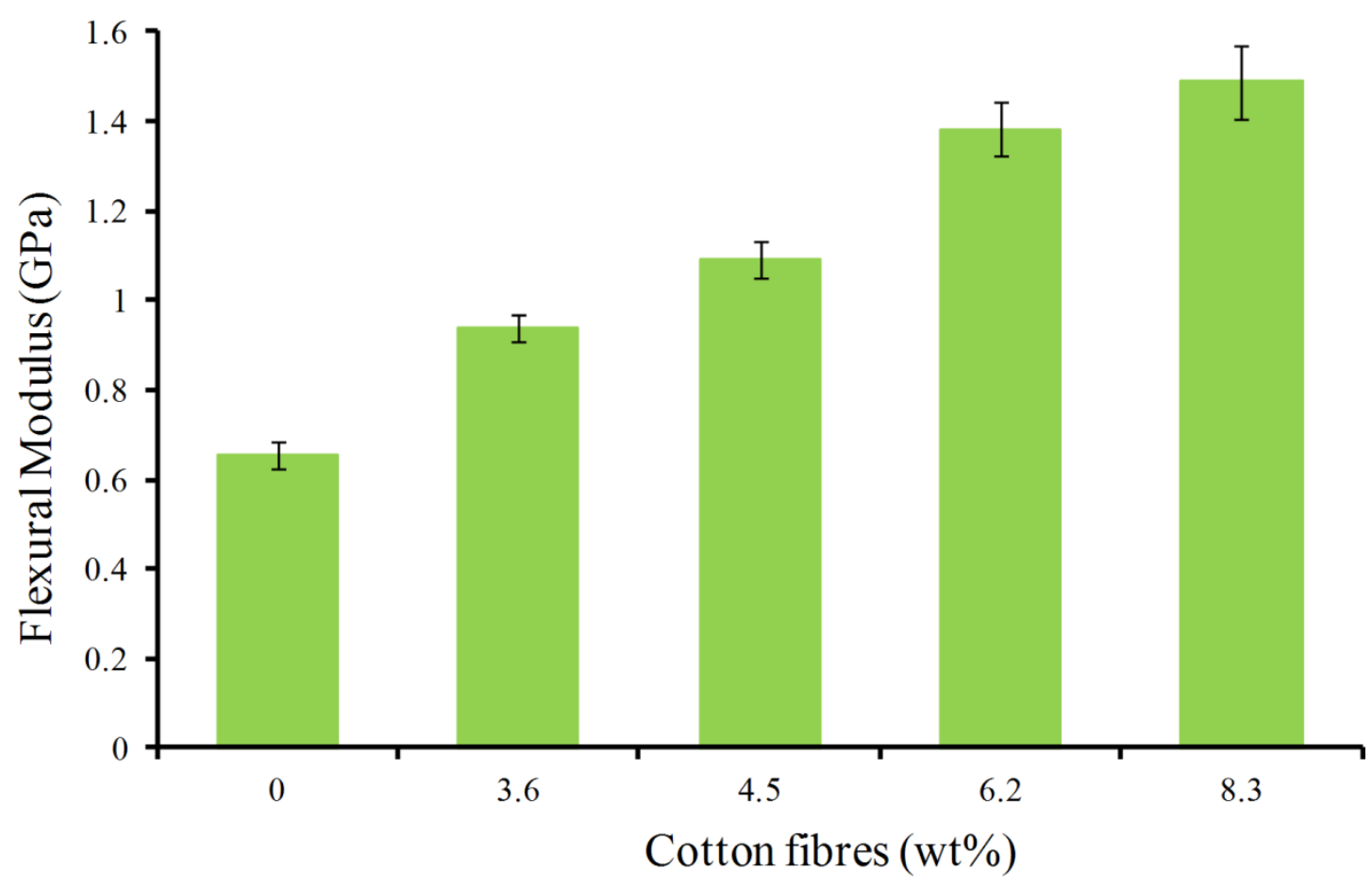


Fig. 4

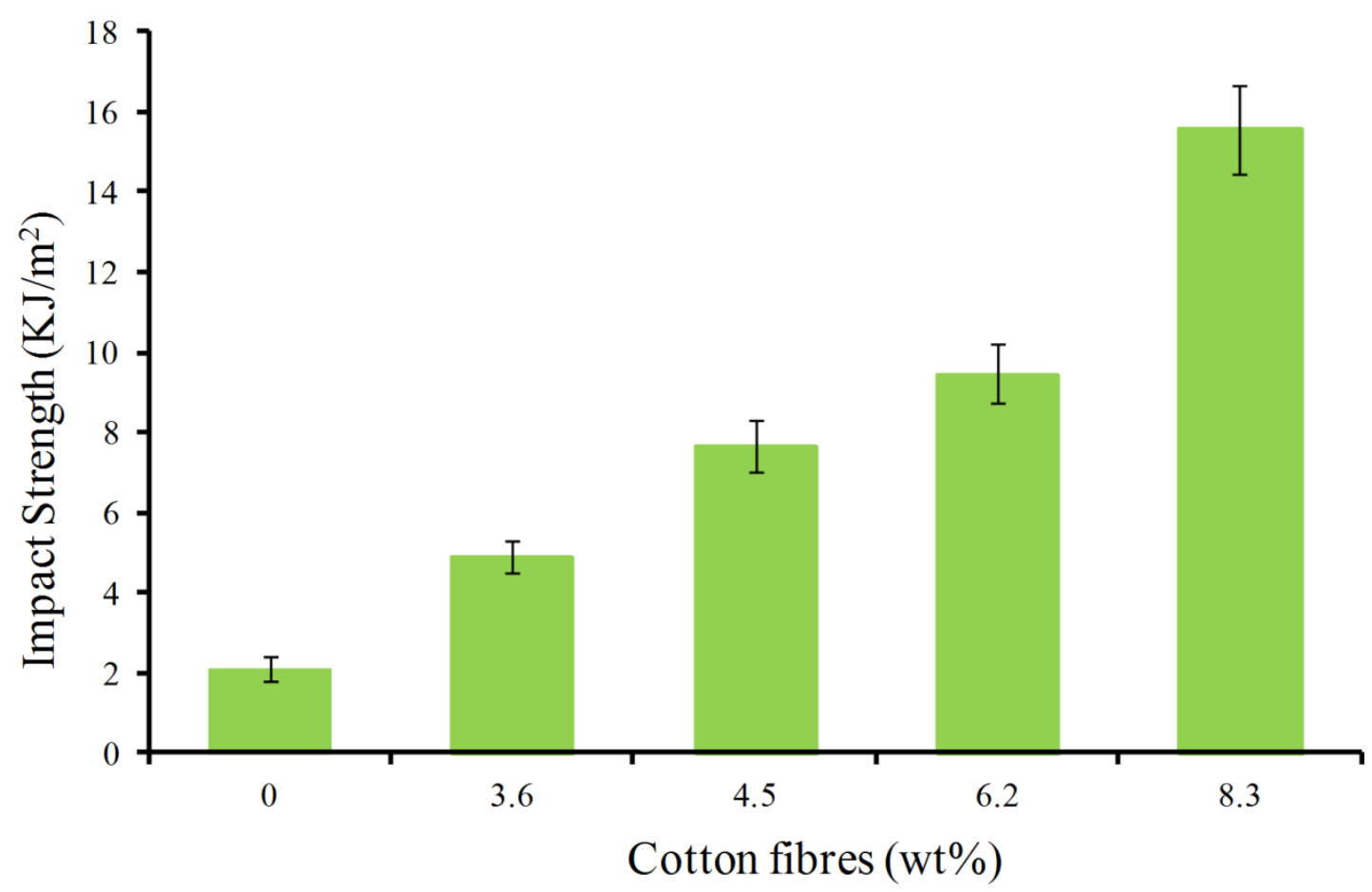


Fig. 5

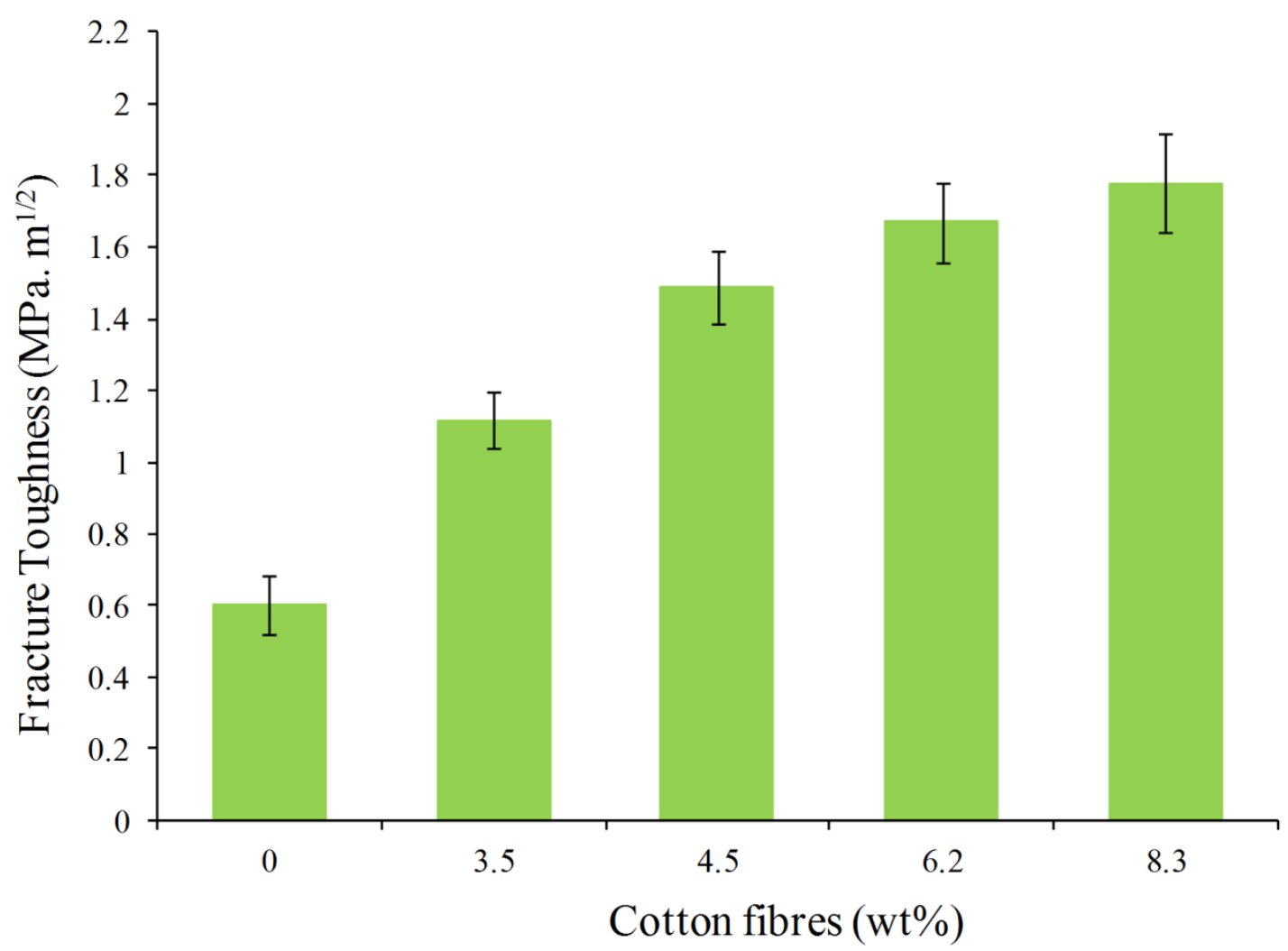


Fig. 6

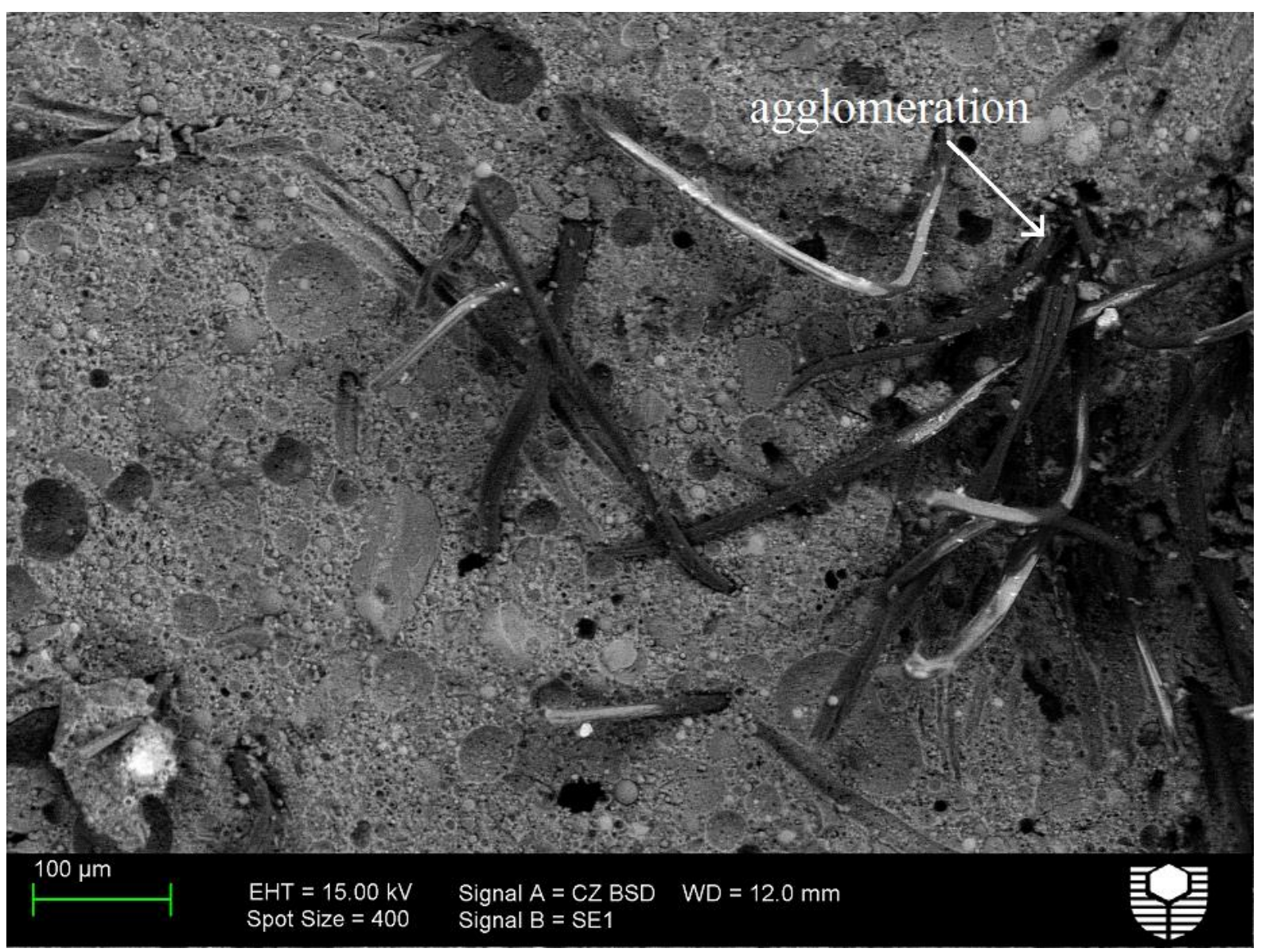


Fig. 7A

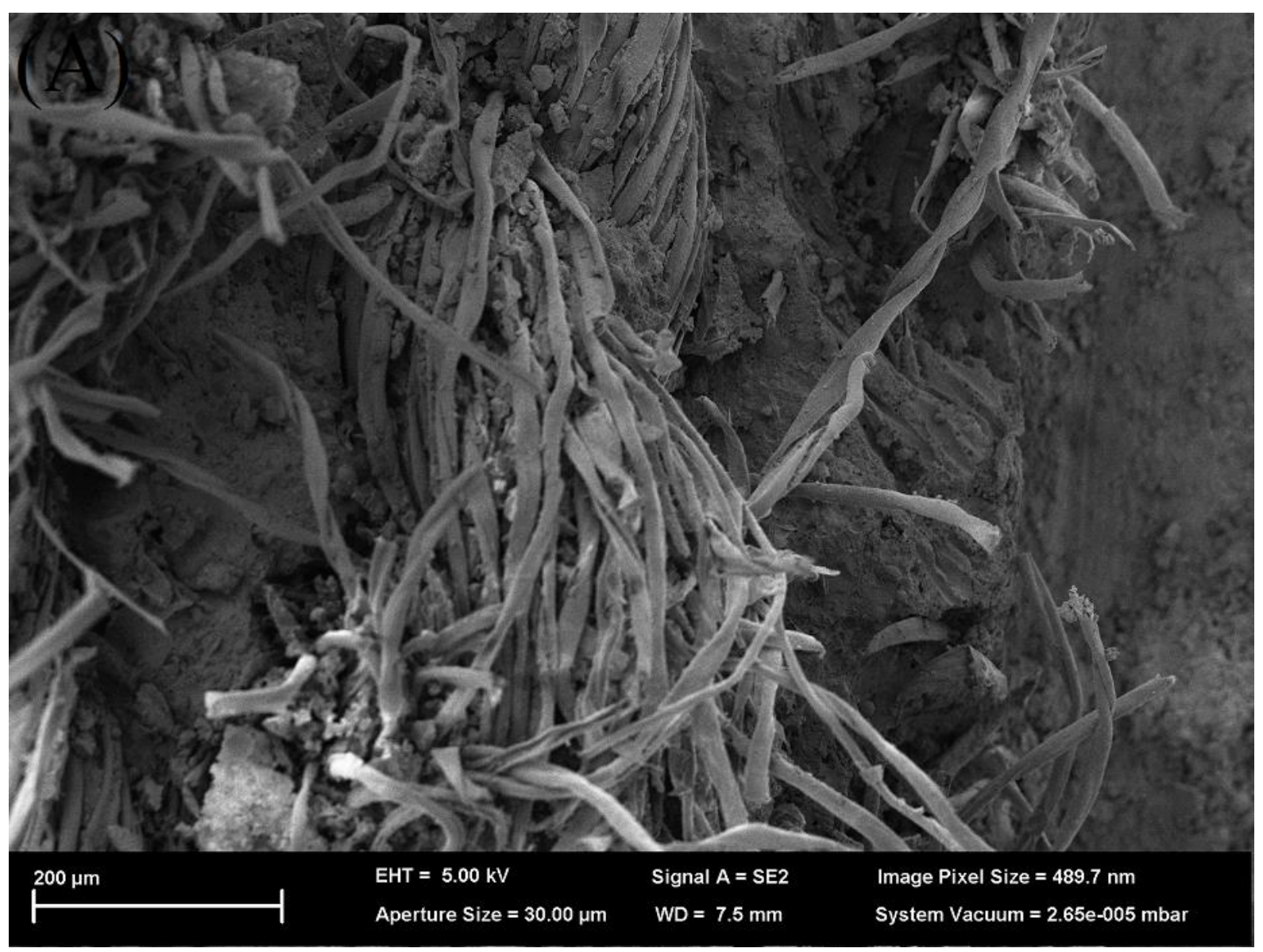


Fig. 7B

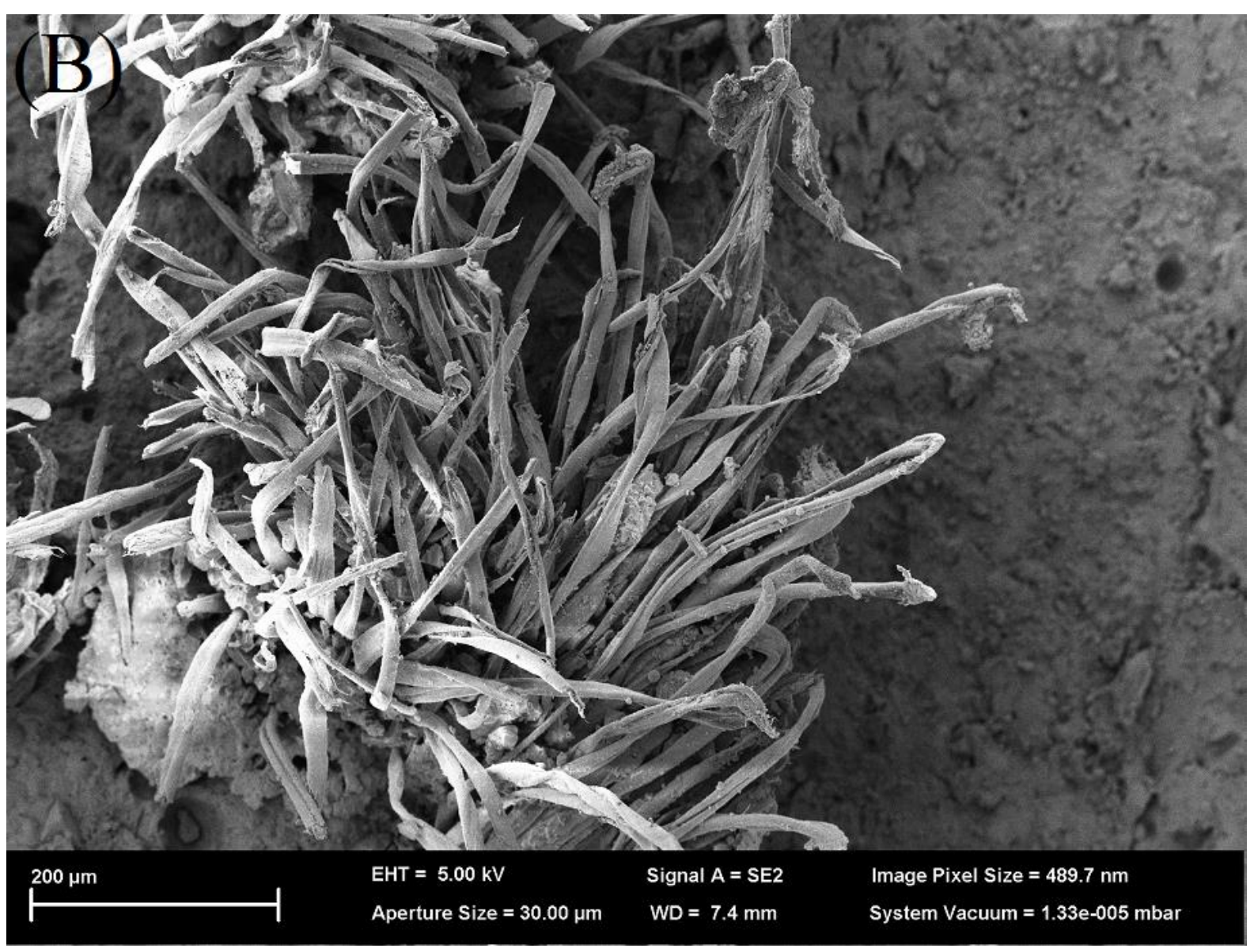


Fig. 7C

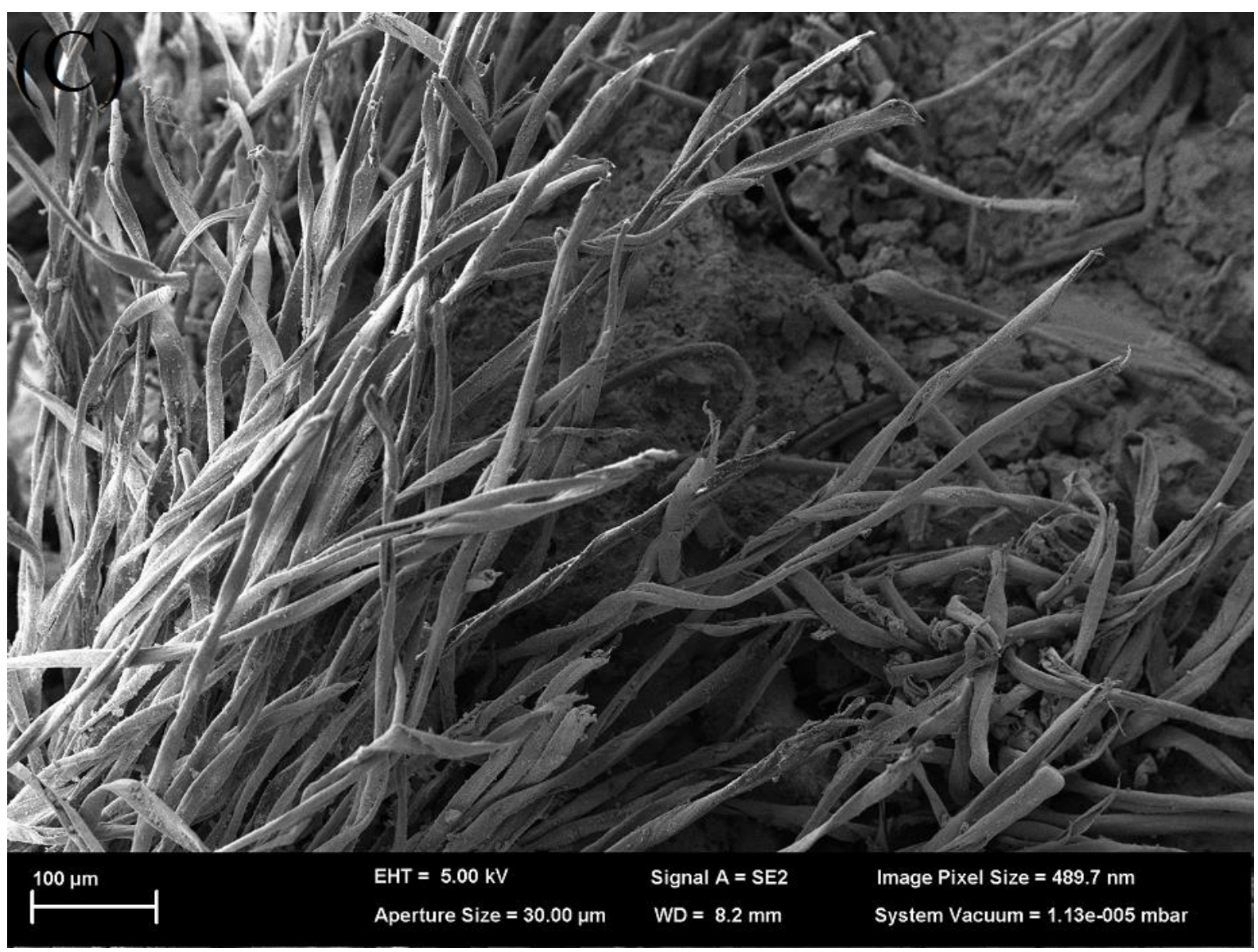


Fig. 7D

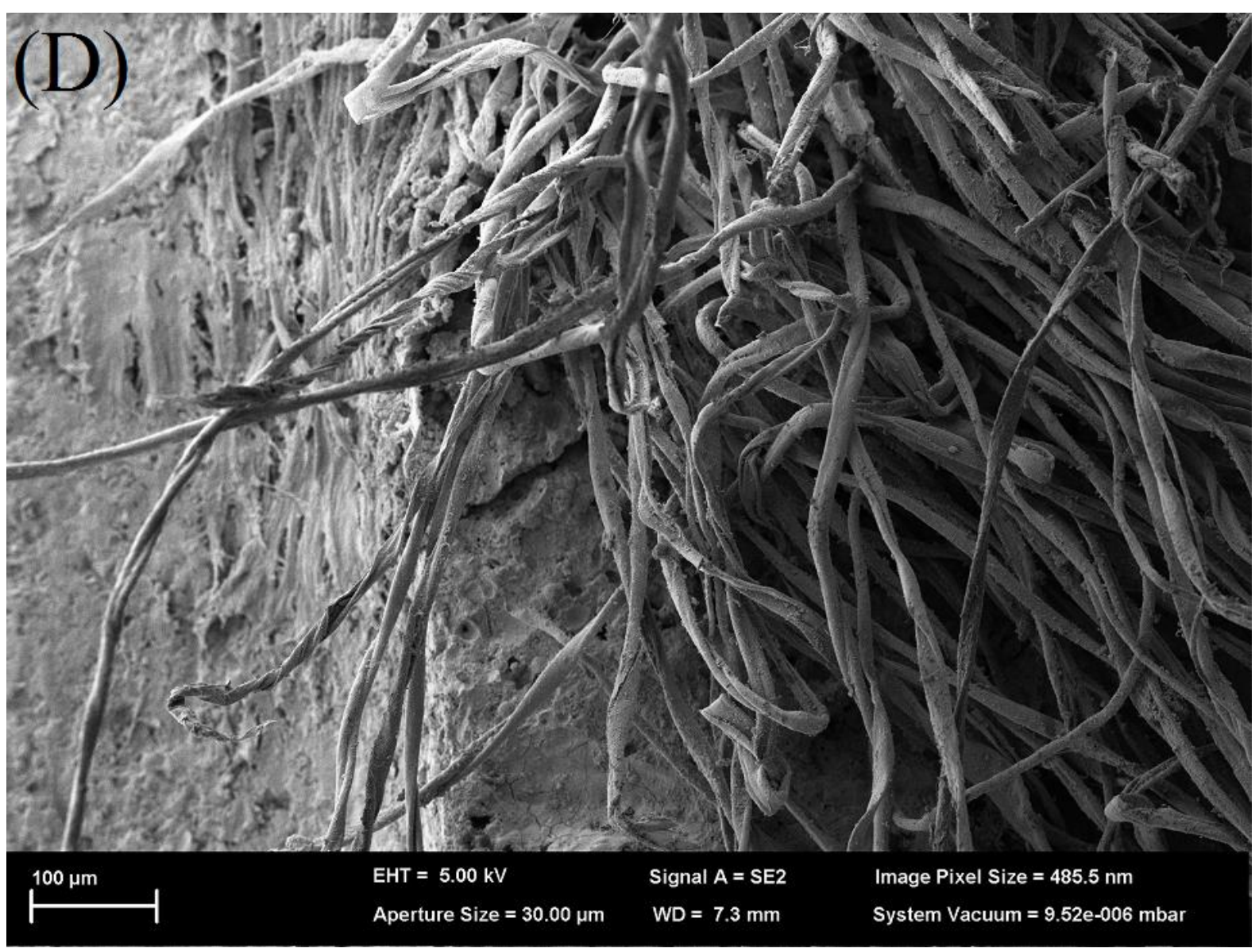


Fig. 7E

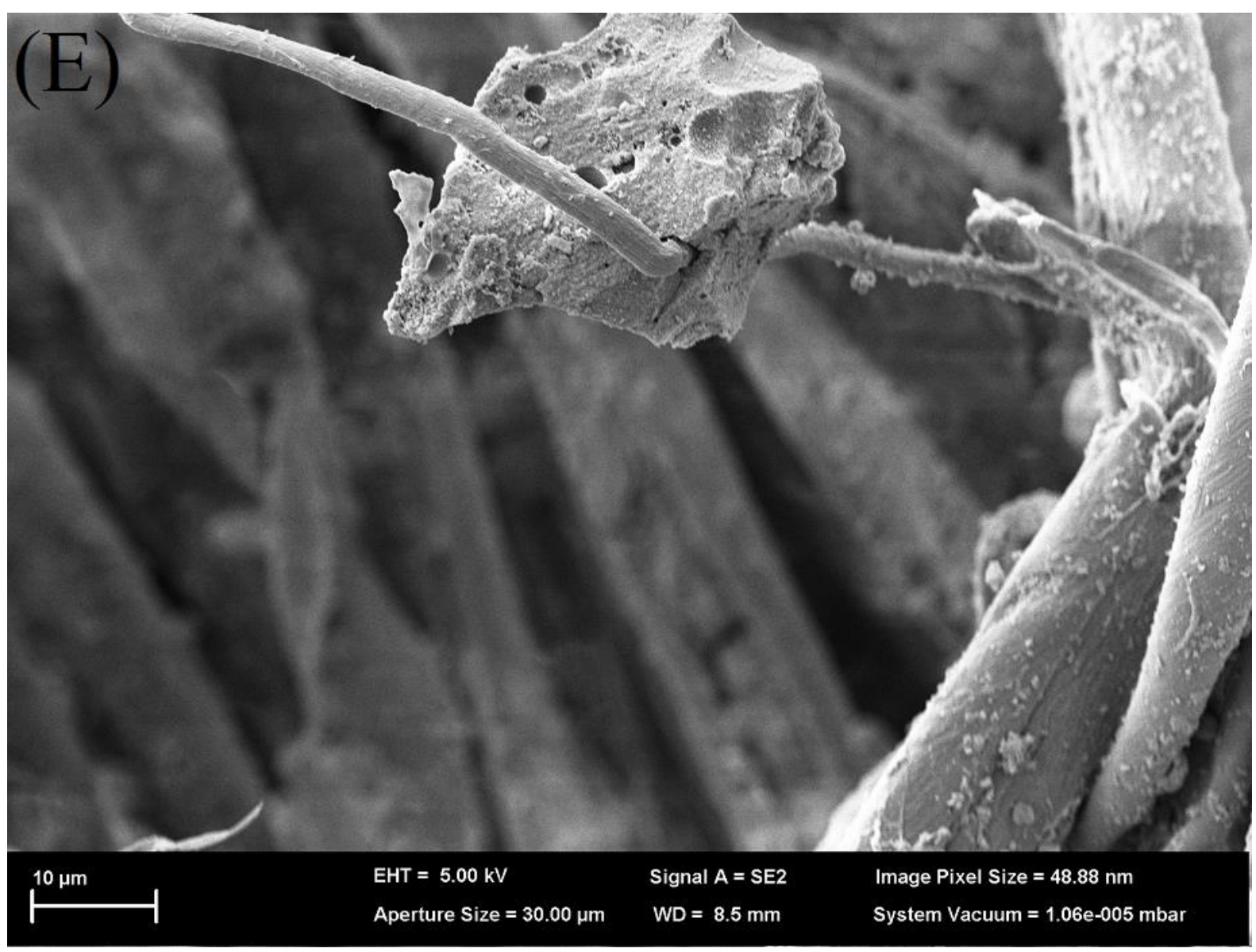


Fig. 7F

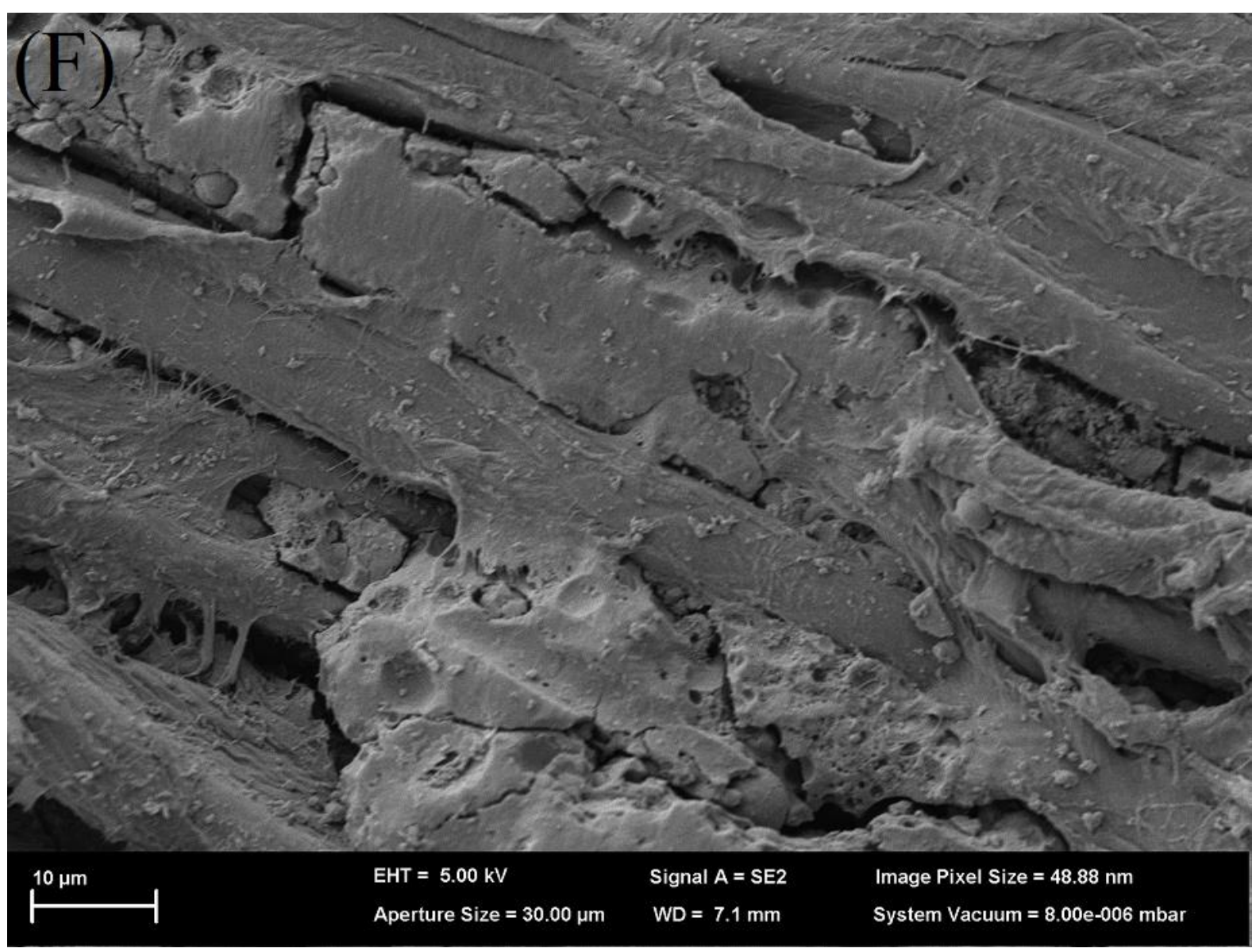


Fig. 7G

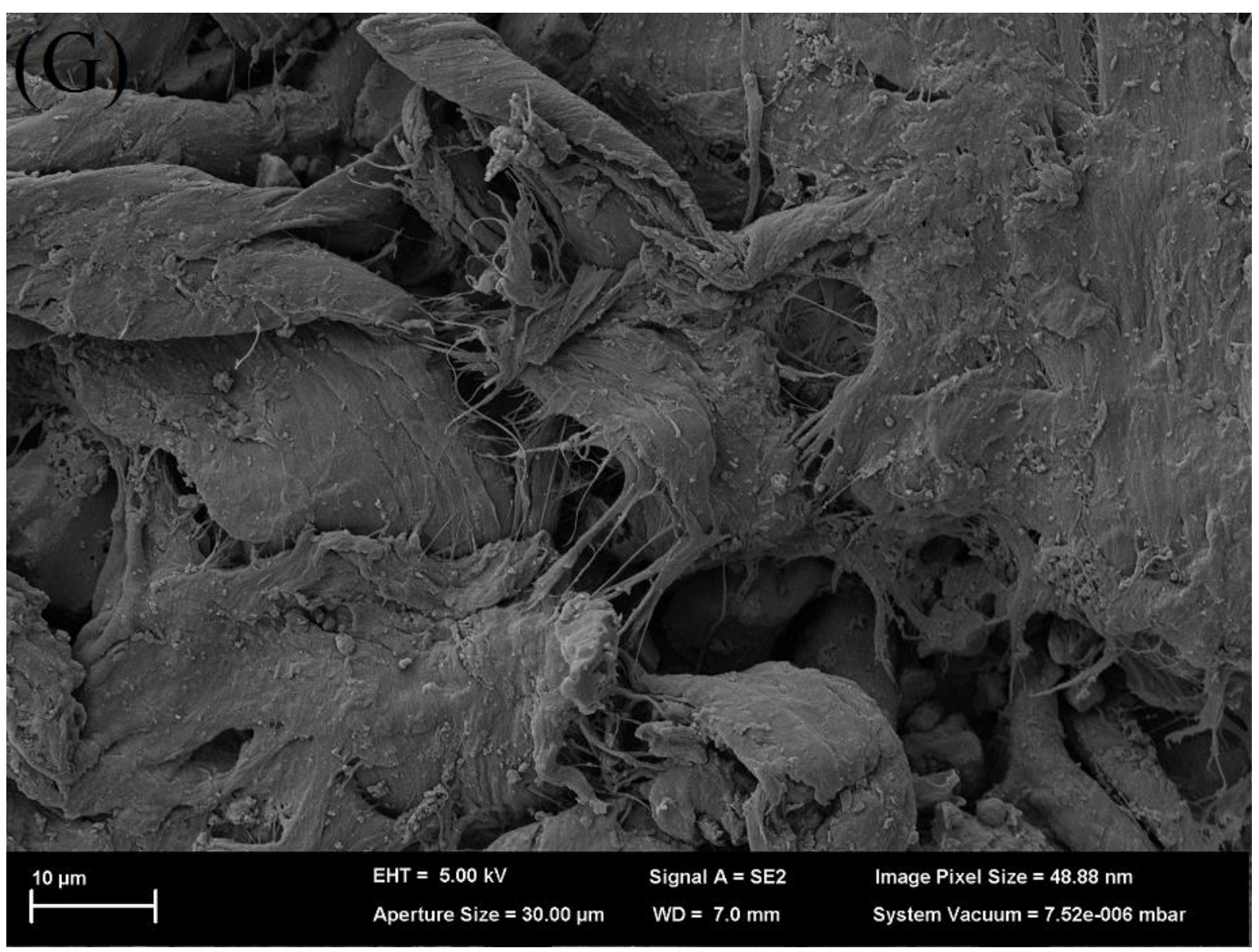


Fig. 8

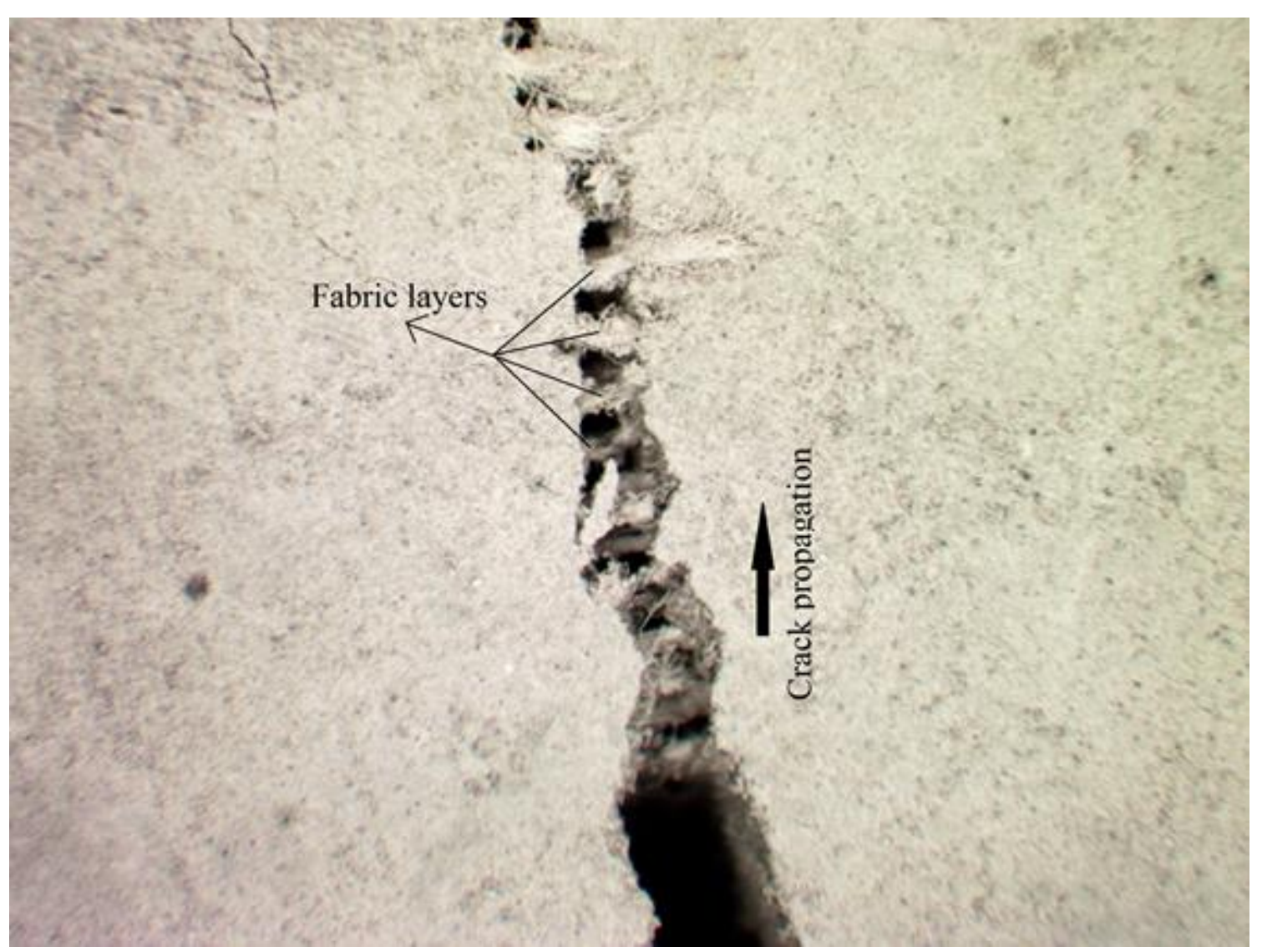

